\title{
openheart Commentary on the Nordic-Baltic bifurcation study IV (randomised comparison of provisional side branch stenting versus a two-stent strategy for treatment of true coronary bifurcation lesions involving a large side branch)
}

\author{
Mirvat Alasnag (D) , ${ }^{1}$ Aditya Bharadwaj, ${ }^{2}$ Khaled Al-Shaibi (D) ${ }^{1}$
}

To cite: Alasnag M, Bharadwaj A, Al-Shaibi K. Commentary on the NordicBaltic bifurcation study IV (randomised comparison of provisional side branch stenting versus a two-stent strategy for treatment of true coronary bifurcation lesions involving a large side branch). Open Heart 2019;6:e001168. doi:10.1136/ openhrt-2019-001168

Accepted 11 November 2019

Check for updates

C Author(s) (or their employer(s)) 2019. Re-use permitted under CC BY-NC. No commercial re-use. See rights and permissions. Published by BMJ.

${ }^{1}$ Cardiology, King Fahd Armed Forces Hospital, Jeddah, Saudi Arabia

${ }^{2}$ Cardiology, Loma Linda University, Loma Linda, California, USA

Correspondence to Dr Mirvat Alasnag, Cardiology, King Fahd Armed Forces Hospital, Jeddah 23311, Saudi Arabia; mirvat@jeddacath.com
Current practice involving bifurcations still recommends a provisional strategy. This stems from two large randomised trials, namely, Nordic bifurcation study (NORDIC I) and the British Bifurcation Coronary Study (BBC ONE). ${ }^{12}$ In these trials a composite end point of all-cause death, myocardial infarction and target vessel revascularisation demonstrated superiority of a provisional strategy. These trials, however, didn't differentiate true bifurcations in which a large side branch had significant disease and those that were not true bifurcations. Additionally, the final kissing inflation and proximal optimisation was not employed in all cases in the twostent strategy arm. Both of these may have impacted the outcomes and remain points of significant controversy when discussing these initial trials. Subsequently, trials such as the European Bifurcation Coronary TWO (EBC TWO) trial compared provisional one-stent technique with an upfront two-stent technique in large true bifurcation lesions (with a side branch diameter $\geq 2.5 \mathrm{~mm}$ ) and significant ostial disease length $(\geq 5 \mathrm{~mm})$. This study found no difference in major adverse cardiovascular events (MACE) between the two techniques. As such, the investigators still conclude that a provisional strategy should be the default. ${ }^{3}$

The NORDIC IV study follows in the heels of the above study. Briefly, this was a randomised multicentre trial comparing a simple provisional strategy with an upfront complex two-stent strategy in true bifurcation lesions (Medina $1,1,1$ or $1,0,1$ or $0,1,1$ ) with a large side branch (main vessel diameter $\geq 3.0 \mathrm{~mm}$ and side branch diameter $\geq 2.75 \mathrm{~mm}$ ). Randomisation was $1: 1$ and occurred after wiring both vessels. The primary endpoint was a composite of MACE at 6 months. Secondary endpoints included a composite MACE endpoint at 2 years, all-cause mortality, cardiac death, nonprocedural myocardial infarction, clinically indicated target lesion revascularisation or target vessel revascularisation, and definite, probable or possible stent thrombosis. The primary endpoint was $5.5 \%$ versus $2.2 \%$ for provisional versus complex strategy, respectively. MACE at 2 years was $12.9 \%$ versus $8.4 \%$ for provisional versus complex strategy. Both endpoints did not meet statistical significance. The difference in MACE at 2 years was primarily driven by target lesion revascularisation. The complex two-stent strategy had a less angiographic stenosis of the side branch with higher procedure time, fluoroscopy time, contrast volume and number of stents. Overall this trial was underpowered to establish superiority.

One limitation that may have confounded outcomes was the use of 'Cypher Selectt' (Cordis, USA) in the first 225 patients and the Xience V or Xience Prime, everolimus eluting stents (Abbott, USA) in the remaining 225 patients. Analysis of the subgroup treated with newer generation drug eluting stents demonstrated a MACE rate of $12.0 \%$ versus $5.6 \%$ with provisional versus complex techniques. This too didn't reach statistical significance. Note, this was not prespecified. Whether these results persist using a variety of different stent platforms including ultrathin stent struts, biodegradable polymers or even dedicated bifurcation 
stents remains unknown. Another limitation, which the investigators allude to in their discussion, is the lack of consistency in the use of intracoronary imaging or physiology to guide revascularisation (emphasised at follow-up and not index procedure). A visual assessment of vessel size and per cent stenosis at the index angiogram is no longer contemporary practice. The quantitative coronary analysis of restenosis was binary with a cut-off of $50 \%$ and was un-blinded. Both intracoronary imaging and physiological assessment of side branches is current practice and recommended in the 2018 European Bifurcation Club Consensus Statement. ${ }^{4-6}$ Despite these recommendations and multiple studies demonstrating the utility of intravascular imaging, it remains underutilised across the spectrum of percutaneous coronary interventions. While lack of strict adherence to intravascular imaging to guide decisions during bifurcation stenting remains a limitation of the current study, it seems to be more reflective of real world practice. ${ }^{78}$ It is also important to note that proximal optimisation was not standard of practice during the recruitment phase of this trial and once again its utility may have impacted the significance of the results. ${ }^{9}$ Another observation is that antiplatelet therapy was limited to aspirin and clopidogrel; therefore, the antiplatelet regimen remains a point of debate with respect to duration and the more liberal use of a potent P2Y12 inhibitors. Finally, with a very small portion of patients enrolled having left main disease $(1.7 \%$ and $2.3 \%$ of total enrolled had left main stenosis in each arm), the results cannot be applied to left main interventions.

\section{Twitter Mirvat Alasnag @mirvatalasnag and Aditya Bharadwaj @adityadoc1}

Contributors The authors confirm that all the authors contributed to this editorial and none have a conflict of interest.

Funding The authors have not declared a specific grant for this research from any funding agency in the public, commercial or not-for-profit sectors.

Competing interests None declared.
Patient consent for publication Not required.

Provenance and peer review Commissioned; internally peer reviewed.

Open access This is an open access article distributed in accordance with the Creative Commons Attribution Non Commercial (CC BY-NC 4.0) license, which permits others to distribute, remix, adapt, build upon this work non-commercially, and license their derivative works on different terms, provided the original work is properly cited, appropriate credit is given, any changes made indicated, and the use is non-commercial. See: http://creativecommons.org/licenses/by-nc/4.0/.

ORCID iDs

Mirvat Alasnag http://orcid.org/0000-0002-8714-0334

Khaled Al-Shaibi http://orcid.org/0000-0002-4572-944X

\section{REFERENCES}

1 Hildick-Smith D, de Belder AJ, Cooter N, et al. Randomized trial of simple versus complex drug-eluting stenting for bifurcation lesions. Circulation 2010;121:1235-43.

2 Steigen TK, Maeng M, Wiseth R, et al. Randomized study on simple versus complex stenting of coronary artery bifurcation lesions: the Nordic bifurcation study. Circulation 2006;114:1955-61.

3 Hildick-Smith D, Behan MW, Lassen JF, et al. The EBC two study (European bifurcation coronary two): a randomized comparison of provisional T-Stenting versus a systematic 2 stent Culotte strategy in large caliber true bifurcations. Circ Cardiovasc Interv 2016;9.

4 Kang S-J, Kim W-J, Lee J-Y, et al. Hemodynamic impact of changes in bifurcation geometry after single-stent cross-over technique assessed by intravascular ultrasound and fractional flow reserve. Catheter Cardiovasc Interv 2013;82:1075-82.

5 Watanabe M, Uemura S, Sugawara Y, et al. Side branch complication after a single-stent crossover technique: prediction with frequency domain optical coherence tomography. Coron Artery Dis 2014;25:321-9.

6 Lassen JF, Burzotta F, Banning AP, et al. Percutaneous coronary intervention for the left main stem and other bifurcation lesions: 12th consensus document from the European bifurcation Club. Eurolntervention 2018;13:1540-53.

7 Ahn J-M, Kang S-J, Yoon S-H, et al. Meta-Analysis of outcomes after intravascular ultrasound-guided versus angiography-guided drug-eluting stent implantation in 26,503 patients enrolled in three randomized trials and 14 observational studies. Am J Cardiol 2014;113:1338-47.

8 Smilowitz NR, Mohananey D, Razzouk L, et al. Impact and trends of intravascular imaging in diagnostic coronary angiography and percutaneous coronary intervention in inpatients in the United States. Catheter Cardiovasc Interv 2018;92:E410-5.

9 Hakim D, Chatterjee A, Alli O, et al. Role of proximal optimization technique guided by intravascular ultrasound on stent expansion, stent symmetry index, and side-branch hemodynamics in patients with coronary bifurcation lesions. Circ Cardiovasc Interv 2017;10. 